\title{
O DIREITO À SAÚDE: UMA ANÁLISE COMPARATIVA DA INTERVENÇÃO JUDICIAL
}

I - Introdução; II - Que medidas o direito à saúde requer?; III Justiciabilidade do direito à saúde: Textura aberta; Impossibilidade de responsabilização do Judiciário; A incompetência institutional do Judiciário; IV - A proteção judicial do direito à saúde pelas cortes brasileiras, indianas e sul-africanas; Brasil; Índia; África do Sul; V-Conclusão - Bibliografia

\section{$I$ - Introdução}

Em julho 2002, a Suprema Corte da África do Sul determinou que o Estado fornecesse um medicamento anti-retroviral para mulheres grávidas infectadas com o HIV a fim de impedir a transmissão da doença aos seus filhos. A decisão "foi festejada como um dos julgamentos mais significativos da corte desde sua criação em 1994" . Não obstante, o evento não representa nada mais do que uma outra tentativa judicial de garantir o direito à saúde, neste exemplo de crianças sul-africanas.

A intervenção das cortes no direito à saúde é bastante controvertida, mesmo quando este direito encontra-se garantido no elenco constitucional de direitos fundamentais. Apesar de uma crescente aceitação, esta possibilidade ainda é alvo de severas críticas e ainda é tratada como algo fora do comum.

Uma análise cuidadosa de como esta intervenção acontece na prática e de como as cortes brasileiras, sul-africanas e indianas tratam dos pontos problemáticos envolvidos mostrará que algumas dessas críticas são de alguma forma equivocadas.

As sistemáticas de intervenção adotadas por essas cortes diferem entre si, indicando que não há uma estratégia certa ou errada. Eu diria, ao invés, que há maneiras mais fortes ou mais fracas de intervenção pelo Judiciário para proteger o direito à saúde. Mas todas elas merecem alguma atenção, posto que cada uma tem seus pontos fortes e fracos.

1 Jornal inglês The Guardian de 06/07/2002. 
Ocorre que uma melhor compreensão dessas estratégias significa uma oportunidade de corrigir erros e fortalecer determinados pontos, conduzindo a um mecanismo protetor mais eficiente a ser aplicado em futuras situações. Além disso, as experiências examinadas podem representar um ponto de partida para outras cortes que enfrentam reivindicações similares e que estão dispostas a contribuir para a implementação e fortalecimento do direito à saúde.

Mas antes da comparação dos métodos concretos de proteção, procurarei explicar as principais obrigações relacionadas com o direito à saúde e examinar os argumentos teóricos contrários e favoráveis à justiciabilidade - "justiciability" do citado direito.

\section{II - Que medidas o direito à saúde requer?}

Minha finalidade nesta seção é possibilitar uma melhor compreensão das ações que devem ser tomadas pelo Estado para fortalecer e garantir o direito à saúde. Para isso pretendo abordar os pontos problemáticos ligados a tais ações, especialmente a falta de recursos financeiros.

Uma ferramenta muito útil na indicação de medidas necessárias é dada por Brigit Toebes. ${ }^{2}$ Aplicando a "tipologia tripartite" dos direitos humanos especificamente ao direito à saúde, ela esclarece que este direito cria para o Estado três modalidades de obrigações principais: respeitar, proteger e implementar. Enquanto a primeira modalidade consiste em uma obrigação negativa, as últimas duas possuem uma conotação positiva.

$\mathrm{Na}$ primeira categoria, não se espera do Estado o fornecimento de bens ou serviços, mas a sua não intrusão na vida do indivíduo de qualquer forma que possa resultar na redução de sua saúde.

Além disso, baseando-se no princípio da proibição do retrocesso social, uma vez promulgada lei estabelecendo determinadas garantias ao direito à saúde, não é permitido ao Estado suprimi-las sem fornecer uma justificativa razoável. ${ }^{3}$ Este princípio foi aplicado na prática pelo Tribunal Constitucional Português para decidir que Portugal violara o dever de respeitar o direito à saúde quando revogou legislação que estabelecia um departamento nacional da saúde. ${ }^{4}$

A segunda modalidade consiste na obrigação de proteger, que requer que $o$ Estado iniba a ação de todo terceiro que possa violar ou desrespeitar o direito à saúde

2 Brigit Toebes, "The Right to Food" in Economic, Social and Cultural Rights: A Textbook. 2" ed. Eide et. al (eds). Londres: M. Nijhoff. 2001, pág. 178.

3 J. J. Gomes Canotilho defende este princípio em sua obra Direito Constitucional, Coimbra, Livraria Almedina, 1989, pág. 449.

4 "a partir do momento que o Estado cumpre (total ou parcialmente) as tarefas constitucionalmente impostas para realizar um direito social, o respeito constitucional desta deixa de consistir (ou deixa de consistir apenas) numa obrigação positiva, para se transformar ou passar também a ser uma obrigação negativa. O Estado, que estava obrigado a actuar para dar satisfação ao direito social, passa a estar obrigado a abster-se de atentar contra a realização dada ao direito social" - Acórdão do TC 39/84 (DR, I, 05/05/84). 
de um indivíduo. Como exemplo, pode-se mencionar a obrigação do Estado de assegurar que as empresas não deixem seus empregados trabalhar em circunstâncias que podem trazer qualquer risco substancial à saúde dos mesmos.

Por fim, existe a obrigação de implementação que institui para o Estado o dever de facilitar ou fornecer diretamente bens e serviços para suprir as necessidades básicas da sociedade. Aplicado ao direito à saúde, isto significa que se espera do Estado a disponibilização de serviços ligados à saúde, assim como a implantação de uma política de saúde eficaz.

$\mathrm{Na}$ realidade, esta última obrigação é a que traz o maior ônus para o Estado, porque exige do mesmo mais do que mera abstenção ou adoção de medidas que impeçam terceiros de danificar a saúde de outros indivíduos. Mais do que isso, requer-se do Estado nesta área a realização de ações que aumentem o nível de proteção já oferecido, melhorando, com isso, o sistema da saúde de forma geral. Assim, por exemplo, se o Estado fornece de graça medicamentos para pessoas HIV-positivas estará implementando o direito à saúde.

Vale aqui esclarecer que tais medidas podem ser concretizadas progressivamente, exceto considerando o núcleo central desse direito, que deve ser implementado imediatamente.

Interessante é o fato de a obrigação de implementar ser geralmente vista como o aspecto distintivo do direito à saúde. As outras duas modalidades de obrigações, portanto, são frequientemente esquecidas. Em consequiência, acredita-se que a implementação do direito à saúde sempre depende da disponibilidade de recursos públicos.

Quanto a isso, não há dúvidas de que o Estado não pode agir além de suas possibilidades financeiras. Ademais, ele pode ter outras áreas prioritárias onde aplicar o dinheiro público, que, infelizmente, não é infinito.

Os recursos financeiros, entretanto, não podem ser vistos como fator decisivo em todos os casos. Há as situações em que o dinheiro não é o problema principal. E mesmo nas situações onde a questão da disponibilidade de recursos se apresenta, deve-se estar ciente de que essa problemática pode também aparecer nos casos que envolvem direitos civis e políticos. Neste momento, oportuno analisar mais a fundo a abrangência do direito à saúde e até que ponto vai a dependência de recursos públicos.

Primeiramente, o direito à saúde não deve ser limitado à obrigação de implementação. Como demonstrado pela tipologia tripartite, ele é muito mais abrangente. Há as obrigações de respeitar e proteger, obrigações que contribuem para a melhoria do direito à saúde e, ao mesmo tempo, não dependem de quantidades significativas de recursos públicos. Por exemplo, o Estado pode ser requisitado simplesmente a regular um setor econômico, medida esta que não é extremamente cara.

Recentemente, cortes indianas analisaram situações concretas onde o Governo não era solicitado a financiar a execução do direito em questão, mas sim a adotar outros tipos de ação. Em um famoso caso levado à Suprema Corte Indiana, Vincent Panikuriangara $v$. India e Outros, ${ }^{5}$ foi formulado um pedido para que o Estado 
indiano melhorasse a política regulatória de importação, manufatura e venda de medicamentos, a fim de assegurar a qualidade daqueles permitidos assim como impedir a presença, no mercado, de itens prejudiciais à saúde.

De acordo com o autor da ação, mesmo considerando que aquilo que era nocivo à saúde humana nos países desenvolvidos também seria nocivo na Índia, alguns medicamentos que tinham sido proibidos por muito tempo nos primeiros eram ainda vendidos livremente na Índia por uma indústria orientada pelo lucro, sem nenhuma tentativa por parte do Governo indiano para impedir tal comércio.

Por ocasião do julgamento, a Suprema Corte da Índia aceitou os argumentos do autor e determinou que "o Governo Central deveria tomar a iniciativa de estabelecer uma autoridade com jurisdição sobre todo o país para regular a manufatura, punindo as irregularidades e falhas encontradas".

Nesta decisão, portanto, não foi requerido que o governo gastasse quantidades significativas de seus fundos para proteger a direito à saúde. Ao invés disso, determinou-se simplesmente a melhora da política estatal e dos mecanismos de controle da indústria farmacêutica.

Situação similar ocorreu no caso Bandhua Mukti Marcha v. de Índia. ${ }^{6}$ Neste caso, diversos empregados estavam ficando doentes porque seus empregadores locatários de minas e proprietários de pedreiras - não observavam seus deveres quanto a algumas leis editadas visando o bem-estar dos trabalhadores. Para terminar com tal situação, tanto o Governo central como determinado estado foram processados por não terem tomado as medidas necessárias para forçar os empregadores a obedecer as citadas normas sociais.

Em sua decisão, a corte esclareceu que garantir o cumprimento de leis protetoras de direitos fundamentais por empregadores era "uma obrigação constitucional que poderia ser exigida do Governo Central e do Estado de Haryana por meio de petição fundamentada no artigo 32 da Constituição".

Aqui, também, o governo não teve que utilizar vultosos recursos públicos para proteger o direito à saúde.

Mesmo em relação à obrigação de implementação, há freqüentemente diversas maneiras distintas de ação, permitindo que o Estado escolha a medida menos custosa. Em determinados casos, é somente uma questão de planejamento e administração eficiente. No mesmo sentido, Henry J. Steiner e Philip Alston entendem que as provisões financeiras diretas e indiretas pelo Estado devem ser vistas por este como uma última opção para cumprir seus deveres econômicos e sociais. ${ }^{7}$ Investidos com um poder discricionário e considerando que quase nunca se espera que o Estado implemente imediatamente os direitos fundamentais, mas sim de maneira progressiva, o mesmo deve ser capaz de encontrar outras soluções antes de optar pela medida que traga gastos públicos elevados.

6 (1984) 2 Supreme Court Reports 67.

7 Henry Steiner e Philip Aiston. International Human Rights in Context: Law, Politics, Morais, Oxford, OUP, 2000, p. 184. 
Ao final, se somente as medidas caras persistirem e o dinheiro público não estiver verdadeiramente disponível, nada pode ser feito exceto confiar nos governantes e esperar que, uma vez que se tornem viáveis, essas medidas sejam adotadas. O que não é possível é forçar o governo a fazer algo se não existe realmente dinheiro em caixa.

Uma situação diferente ocorre quando, apesar da negativa do Estado, há provas de que os recursos existem ou que as prioridades escolhidas são claramente ilegítimas. Esta discussão, entretanto, não cabe neste momento, razão pela qual voltarei a ela mais tarde.

Em segundo lugar, mesmo considerando que a implementação do direito à saúde requer medidas dispendiosas, deve-se recordar que a necessidade de recursos públicos não existe somente para os direitos sócio-econômicos. Os direitos civis e políticos de alguma forma também dependem desses recursos, e tal fato nunca foi considerado um obstáculo a sua garantia.

Mesmo envolvendo despesas elevadas, a Suprema Corte dos Estados Unidos garantiu assistência jurídica em todos os processos criminais, por entender que tal assistência não era um luxo, mas uma necessidade. ${ }^{8} \mathrm{O}$ direito ao devido processo legal é apresentado por DM Davis como outro exemplo de altos custos para a proteção de direitos civis, uma vez que "o Estado deve garantir a existência de uma corte, juizes independentes, força policial assim como um sistema penitenciário". 9

Ciente desses dois aspectos, o Estado deve fazer o máximo possível, seja no campo do respeito, da proteção ou da implementação.

No caso de nada ser feito, mesmo diante de provisões constitucionais, surge a idéia da intervenção judicial para forçar a ação do Estado. Apesar dos argumentos contrários a essa tese, tentarei demonstrar que, com alguns limites, o envolvimento do Judiciário é possível e, mais que isso, desejável.

\section{III - Justiciabilidade do direito à saúde}

No presente capítulo, será analisada a possibilidade de cortes judiciais proferirem decisões para obrigar o Governo a adotar medidas garantidoras do direito à saúde. Ou seja, é hora de analisar a justiciabilidade — "justiciability" — do direito à saúde.

Como esta idéia é muito contestada, pretendo analisar as críticas mais comuns contra ela dirigidas, para, ao final, demonstrar que as cortes judiciais são capazes e devem agir, desde que respeitem as funções privativas do Executivo e do Legislativo.

Justiciability pode ser compreendida como a possibilidade de um direito ser garantido por juízes mesmo quando não há uma legislação ordinária que o regule, mas somente provisões constitucionais. Pode-se observar, conseqüentemente, que é

8 Guideon versus Wainright -83 S. Ct.. 792.

9 DM Davis. "The case against the inclusion of social-economic rights in a Bill of Rights Except as Directive Principles" (1992), South African Journal of Human Rights 475 - Tradução livre. 
um conceito relacionado à competência das cortes. É por isso que, como Matthew Craven explica, justiciabilidade não deve ser considerada como uma característica inerente ao direito em si. ${ }^{10}$

Uma vez esclarecido tal conceito, passarei a examinar as razões favoráveis à intervenção judicial em determinadas circunstâncias para garantir o direito à saúde e porque há tanta discordância quanto a esta possibilidade.

Vale ressaltar, entretanto, que essa discordância é mais acentuada com relação às obrigações positivas relacionadas ao direito à saúde, que são as obrigações de proteção e implementação impostas ao Estado.

A respeito das obrigações negativas, concorda-se de uma forma geral que elas não variam estruturalmente dos direitos civis e políticos, e há um aumento da aceitação da justiciabilidade destes últimos. ${ }^{11}$ Analisando a mesma questão, Toebes sustenta que "obrigações de abstenção pelo Estado de atividades prejudiciais à saúde, tais como atividades poluidoras, são justiciáveis." 12

Assim, pode-se notar que os pontos problemáticos encontram-se exatamente nas obrigações de proteger e implementar o direito em tela, pela natureza positiva das mesmas. Os críticos dizem que o direito à saúde é um termo indeterminado em relação aos benefícios que podem ser concedidos e deveres positivos que podem ser impostos. Por esta razão, a ação legislativa é vista como uma precondição para decisões judiciais. Em segundo lugar, alegam que, um vez que tais decisões podem ter um impacto no orçamento e são essencialmente decisões políticas, não devem estar dentro da função das cortes. Em consequiência, de acordo com tais críticos, a intervenção judicial neste campo conduziria a uma violação da democracia e do princípio da separação dos poderes.

\section{Textura aberta}

A indeterminação ou a textura aberta do direito à saúde é indicada como um obstáculo para a sua análise pelas cortes judiciais.

Os direitos sócio-econômicos de forma geral são garantidos de uma maneira indeterminada, tal como saúde, moradia, alimentação. Assim, supondo que uma Constituição não traga uma explanação detalhada sobre o que pode ser compreendido como o direito à saúde nela garantida, como podem os juízes decidir seu real conteúdo?

10 Mathew Craven, "The Justiciability of Economic, Social and Cultural Rights", em Economic, Social and Cultural Rights: Their Implementation in the United Kingdom. R. Burchill, D. Harris \& A. Owers, (eds.) 1999, p. 1.

11 Governos ainda criticam o controle jurisdicional de forma geral, como pode ser visto do comentário de um Secretário de Estado Britânico, David Blanket, após o julgamento do caso $\mathrm{R}(Q)$ e Outros (2003 EWHC 195 (Admin)) "Francamente, estou pessoalmente cansado de ter que lidar com a situaçāo onde o Parlamento debate questões e os juizes posteriormente vêm reformá-las". The Guardian, 20/02/2003.

12 Brigit Toebes. Op cit., p. 182. 
Tal intervenção, portanto, geraria um risco de se assegurar aos indivíduos benefícios não pretendidos originalmente pela Constituição, a lei das leis, porque os juízes poderiam aplicar suas próprias idéias e valores na interpretação desse direito.

Este argumento, contudo, não é forte o bastante para impedir a justiciabilidade do direito à saúde.

Em primeiro lugar, a conceituação do direito à saúde é uma tarefa complexa, mas não impossível. Há vários documentos internacionais como a Convenção Internacional de Direitos Econômicos, Sociais e Culturais, assim como Comentários Gerais de corpos internacionais hábeis a serem usados como ferramentas úteis para tal finalidade.

Tendo como ponto inicial tais instrumentos e as realidades de cada país, os juízes podem desenvolver um conceito detalhado do direito à saúde.

$O$ conceito de núcleo central deve ser lembrado neste momento. Ele significa, como o próprio nome sugere, o nível mínimo essencial de saúde que deve ser fornecido pelo Estado aos indivíduos. Se for possível um fornecimento mais completo, naturalmente pode o Estado fazê-lo, mas nunca deve o mesmo fornecer menos do que este limite mínimo.

Esta idéia é bastante útil, pois facilita a conceituação do direito, já que mais fácil determinar somente os aspectos centrais de um direito. Através deste mecanismo, portanto, os juízes podem traduzir o vago "direito à saúde" em benefícios concretos.

E como se sabe, esse processo de interpretação não é algo novo, razão pela qual não deveria causar tantas surpresas e polêmicas. A mesma sistemática é prática comum na garantia de direitos civis e políticos, posto que estes também não são sempre perfeitamente detalhados e conceituados.

Mas antes de analisar esta afirmação, vou mais longe ainda para, mencionando H. Hart, defender que a abertura e a indeterminação são características de sistemas legais em general. Citando Herbert Hart, "todas as regras envolvem o reconhecimento ou a classificação de casos particulares como exemplos de termos gerais" Consequientemente, ao decidir o conteúdo de "preço justo" ou "condições de segurança", por exemplo, os juízes podem ser apresentados situações que se encaixam perfeitamente nestas idéias, mas também podem se deparar com situações encontradas em uma área de "penumbra própria da incerteza". Assim, a prestação jurisdicional é uma atividade que naturalmente envolve a determinação do sentido e da extensão de termos gerais.

Retornando aos direitos civis e políticos, vale esclarecer que eles são geralmente apontados como o modelo da certeza. Assim, aceita-se que as cortes possuem pouca influência subjetiva na aplicação dos mesmos a casos concretos. Ademais, é dito que, em tais casos, a ordem judicial é sempre no sentido de impedir o governo de fazer o que vem fazendo. ${ }^{14}$

13 Herbert Hart. O Conceito de Direito. Lisboa: Fundação Calouste Gulbenkian, pág. 134.

14 Craig Scott e Patrick Macklem. "Constitutional Ropes of Sand or Justiciable Guarantees? Social Rights in a New South Africa Constitution", 141 University of Pennsylvania Law Review 1 a 45. 
O problema é que as coisas não são tão simples quanto parecem, já que mesmo na área dos direitos civis e políticos também existe a possibilidade de indeterminação e de vagueza.

Quando as cortes têm que decidir que tipo de discurso está sob a proteção da liberdade de expressão não há nenhuma certeza envolvida. $O$ direito de privacidade é um outro exemplo. ${ }^{15}$ É ele relacionado somente com o controle da informação ou significam também o "direito a ser deixado sozinho" ${ }^{16}$ Finalmente, é importante mencionar a idéia do devido processo legal. Em decorrência de sua generalidade, a Suprema Corte americana, além do devido processo legal no aspecto procedimental extraiu da Décima Quarta Emenda o conceito do devido processo legal substantivo, conceito este aplicado pela mesma corte como um teste para identificar leis violadoras de direitos fundamentais.

Como pode ser visto, devido à imprecisão das palavras escolhidas para representar certos direitos civis e políticos, o Judiciário tem determinado o significado e limite destes mesmos direitos. Não há, conseqüentemente, neste aspecto, nenhuma diferença significativa entre adjudicar os direitos civis e os sócio-econômicos.

Além disso, o desenvolvimento do conteúdo do direito à saúde é uma questão de tempo. Não se pode esquecer que os direitos sócio-econômicos foram constitucionalizados pouco tempo atrás. Por esta razão, o Judiciário está ainda aprendendo a lidar com eles e alguma melhora ocorrerá somente se não se impedir os juízes de continuarem esse processo se aprendizado. Nas palavras de Scott e de Macklem: "justamente como seria um erro supor que em 1800 as cortes nos Estados Unidos tinham um profundo conhecimento do que estava abrangido pela igualdade perante a lei, assim também seria um erro supor uma precisão judicial com relação às obrigações legais que podem fluir de direitos, tal como direito à educação, demasiado cedo no história constitucional desses direitos." 17

\section{Impossibilidade de responsabilização do Judiciário}

Argumenta-se também que este tipo de intervenção judicial causa danos sérios à democracia já que dá a juízes o poder de criar leis e direitos.

Uma característica essencial da democracia é o Legislativo, que é o corpo representativo da sociedade, e como tal é o principal responsável pela formulação das regras que vão governar todos os indivíduos e dos direitos que serão instituídos em favor dos mesmos. A idéia central, portanto, é autogoverno. O Executivo, depois das linhas gerais estabelecidas pela legislatura e dentro de seu poder discricionário,

15 Em relação à proteção da privacidade no Reino Unido, David Feldman sustenta que “até recentemente, nem os juizes nem os legisladores tinham pensado em um direito à privacidade como tal. A principal razão para isso era a dificuldade de se definir privacidade com alguma clareza." In David Feldman. Civil Liberties and Human Rights in England and Wales. Oxford: OUP. 2002, p. 544 .

16 Thomas Cooley, A Treatise on the Law of Torts, Chicago, Callaghan and Co. 1988, p. 29.

17 Craig Scott e Patrick Macklem. Op cit. 72. 
estabelece as políticas públicas, que no final também criam regras obrigatórias para a sociedade.

O Judiciário, por sua vez, compreende um corpo não-eleito. Devido a essa distinção, tem um papel completamente diferente em um sistema legal. Isto consiste principalmente na aplicação aos casos concretos das leis discutidas e aprovadas por membros eleitos do Poder Legislativo.

Ao mesmo tempo, entretanto, entendo que há boas razões para termos juízes interferindo e decidindo sobre o direito à saúde, se a garantia deste direito for realmente desejada.

Como esclarecido pelo juiz da Corte Constitucional da África do Sul, Albie Sach, os direitos sócio-econômicos carregam a idéia de que cada indivíduo é titular de alguns direitos básicos que não podem ser ignorados sob nenhuma circunstância e independente do partido político no poder ${ }^{18}$ Este grupo de direitos centrais tem que ser garantido a todos sem exceção.

Devido a isto, Sach sustenta que a accountability - possibilidade de responsabilização - dos representantes do povo transforma-se em uma ameaça para certos grupos da sociedade. Os políticos, a fim de se tomarem representantes, necessitam ser eleitos e freqüentemente vão querer ser eleitos novamente. Neste processo, é natural que eles se comprometam e procurem o apoio da maioria ou dos poderosos. Se não se toma difícil ser escolhido.

Após serem eleitos, os representantes tendem a representar os interesses de seu eleitorado e podem se esquecer daqueles sem influência, das minorias marginalizadas. Estas minorias podem até mesmo se tomar alvo de políticas criadas pelos próprios representantes, com base em preconceitos da maioria da sociedade.

Por causa disto, é crucial que um órgão sem nenhuma aspiração política, que não se compromete e que, ao menos na teoria, é independente do governo, esteja lá para garantir direitos básicos para as minorias que não possuem acesso fácil às instituições democráticas.

Ciente desta necessidade, o juiz da Suprema Corte Americana, Harlan F. Stone, decidiu no caso United States versus Carolene Products Co. ${ }^{19}$ (em sua famosa nota de rodapé número quatro) que "essa corte deve também se preocupar com o que as maiorias fazem às minorias, particularmente mencionando as leis 'direcionadas a' minorias religiosas, nacionais e raciais e aqueles infectados por preconceito contra eles". 20

O fato de os juízes constituírem uma minoria impondo suas decisões, muitas vezes, contra a vontade da maioria da sociedade é de pouca importância aqui, especialmente porque tais decisões são tomadas exatamente com base em normas constitucionais.

18 Albie Sach. Palestra intitulada "Jusficiability of Social, Economic and Cultural Rights" apresentada na LSE em 27/02/2003.

19304 US 144.

20 John Hart Ely. Democracy and Distrust: A Theory of Judicial Review. Londres: Harvard University Press. 1980, p.76. 
Diante disso, entendo que, na realidade, o papel do Judiciário é extremamente útil em uma democracia, uma vez que força o respeito à Constituição e impede que uma sociedade democrática se transforme em mero governo majoritário.

\section{A incompetência institutional do Judiciário}

Outra critica à justiciabilidade do direito à saúde é no sentido de tal possibilidade permitir que juízes decidam não apenas onde mas também quanto de recursos públicos o Executivo e o Legislativo devem gastar. Com isso, diz-se que com a tese da justiciabilidade os juízes poderiam criar um ônus financeiro muito pesado para o Estado.

Para evitar esse risco, argumenta-se que tais decisões devem permanecer dentro da esfera privada dos legisladores e dos administradores públicos. Esses são os que possuem conhecimento técnico sobre quanto o Estado pode gastar e, por essa razão, estão em posição melhor do que os juízes para tomar decisões nesta seara.

A fraqueza deste argumento, contudo, é que há aspectos do direito à saúde que não requerem do Estado utilização significativa de recursos públicos. ${ }^{21}$ Além disso, determinações judiciais para a utilização desses recursos não são encontradas exclusivamente em casos envolvendo o direito à saúde. ${ }^{22}$

$\mathrm{Na}$ realidade, como Etienne Mureinik explica, o que é especial em relação ao direito à saúde é a possibilidade dele ser protegido através de maneiras diferentes, não havendo apenas uma única forma correta. ${ }^{23}$

Por tal motivo, na realidade se decide qual política deve ser adotada entre as opções disponíveis, ou seja, são decisões substancialmente políticas, que, portanto, requerem um conhecimento extralegal.

Assim, a questão central da justiciabilidade do direito à saúde refere-se à competência ou não do Poder Judiciário, diante do princípio da separação dos poderes, para tomar decisões materialmente políticas.

Neste momento, Jonathan Feldman nos lembra da coexistência dos dois aspectos do princípio da separação dos poderes - negativo e funcional. ${ }^{24}$

De acordo com o primeiro, a separação dos poderes visa evitar tirania e interferência arbitrária em liberdades individuais. Pela divisão do poder, não haveria somente uma pessoa no controle absoluto do Governo, mas três instituições diferentes, com capacidade suficiente para conter os abusos uma das outras.

21 Vincent Panikuriangara v. Union of India e Bandua Mukti Morcha v. Union of India. V. Seçāo III.

22 Assistência jurídica e o direito a um julgamento justo foram dados como exemplo de direitos civis e políticos que igualmente requerem gastos de recursos públicos. V. Seção III.

23 Etienne Mureinik. "Beyond a Charter of Luxuries: Economic Rights in the Constitution" (1992) 8 South African Journal of Human Rights 464 a 466.

24 Jonathan Feldman. "Separation of Powers and Judicial Review of Positive Rights Claims: The Role of Sate Courts in an Era of Positive Government" 24 Rutgers Law Journal 1057 a 1060. 
Entretanto, o princípio em questão possui uma outra aspiração: eficiência governamental. Procura-se através desta vertente alocar as funções públicas de acordo com as características especiais e as habilidades predominantes de cada poder. Conseqüentemente, as funções seriam atribuídas à instituição mais preparada para executá-la, fazendo com que o Governo se tornasse mais eficiente como um todo. Esta é a separação funcional dos poderes.

Baseado nela, Feldman menciona que "a tarefa da interpretação constitucional é atribuída ao Judiciário, ao invés do Legislativo, porque o primeiro tem uma expertise superior e mais imparcialidade em interpretar o conteúdo e a finalidade das leis." 25

Desta forma, considerando o aspecto funcional, é possível e mesmo desejável que os juízes analisem os casos que envolvem o direito à saúde. Eles podem não entender de questões políticas, mas, por outro lado, têm conhecimento e experiência na determinação do significado de dignidade humana e na aplicação e interpretação da Constituição. Além disso, são imparciais e não se comprometem movidos por interesses eleitoreiros. Assim, como Feldman sustenta, o Legislativo e o Executivo são as instituições ideais para determinar políticas públicas, mas estas devem ser formuladas dentro dos limites estabelecidos pelo Judiciário, considerando os parâmetros positivos encontrados na Constituição.

É fácil ver, conseqüentemente, que o argumento que sugere a incompetência do Judiciário neste campo está baseado unicamente na separação negativa dos poderes. $O$ problema é que este aspecto da doutrina foi elaborado num momento em que o objetivo principal consistia em impedir comportamentos tirânicos e proteger liberdades individuais.

Hoje, contudo, prevalece uma outra realidade. Devido ao reconhecimento dos direitos sócio-econômicos e de sua constitucionalização em algumas jurisdições. Estados não são vistos simplesmente como tiranos, mas também como uma instituição necessária para melhorar a qualidade de vida dos indivíduos e garantir indiretamente as mencionadas liberdades individuais. Isto faz a omissão ao invés da ação uma ameaça em alguns casos.

Em consequiência dessa revolução constitucional, as cortes passaram a decidir quando o Estado "foi muito longe" e também onde ele "não foi longe o suficiente." 26

Por causa dessa mudança de cenário, a separação negativa dos poderes não pode mais ditar sozinha as relações entres os poderes do Estado e, conseqüentemente, não pode ser vista como um obstáculo para a justiciabilidade do direito à saúde. Alguns juristas, entretanto, não aceitam esta possibilidade e, de acordo com uma visão tradicional, limitam o papel do Judiciário à verificação de invasões na esfera dos direitos individuais por parte do poder governamental.

A separação de poderes, contudo, deve ser atualizada e para tanto Feldman sugere a inclusão de obrigações positivas do Estado na sua sistemática. Mas mesmo esta versão mais moderna, segundo ele, não poder ir tão longe a ponto de permitir

25 Ibid.

26 Ibid., p. 1085. 
que juízes formulem políticas públicas detalhadas, já que as funções dos outros dois poderes devem ser respeitadas.

Assim, uma vez que o aspecto negativo da doutrina da separação de poderes não se adequa mais à atual estrutura constitucional, e que o seu aspecto funcional requer a interferência do Judiciário em certas situações, entendo que a justiciabilidade do direito à saúde não significará sempre uma invasão nas funções do Legislativo e do Executivo.

Isto não significa, entretanto, que os juízes podem ignorar as questões discutidas nesta seção. Como advertido por Feldman, deve sempre haver respeito do Judiciário pelo papel dos demais poderes. Mesmo diante da vontade geral de proteger o direito à saúde, as cortes devem ser extremamente cuidadosas para não extrapolarem suas funções institucionais. Logo, os juízes devem interferir somente quando o núcleo do direito à saúde estiver em risco ou quando o Executivo e o Legislativo não souberem utilizar o poder discricionário dado a eles e passarem a atuar de forma abusiva.

Após a análise das três principais críticas à justiciabilidade do direito à saúde: indeterminação dos atributos, impossibilidade de responsabilização e incompetência do Judiciário, é possível concluir que não existe nenhum obstáculo absoluto a esta idéia. Na realidade, desde que os juízes respeitem seus limites, espera-se deles que realmente garantam o direito à saúde.

\section{IV - A proteção judicial do direito à saúde pelas cortes brasileiras, indianas $e$ sul-africanas}

As cortes brasileiras, indianas e sul-africanas têm se comprometido com esse objetivo e vêm desenvolvendo estratégias para alcançá-lo de forma concreta. Neste processo, elas podem cometer alguns erros, e efetivamente cometem, mas, ao menos, já deram um passo importante, superando a resistência inicial à justiciabilidade do direito à saúde, tão comum em sociedades e cortes de Justiça.

Um exemplo de tal resistência é os Estados Unidos. A Suprema Corte americana é contra a intervenção judicial neste campo e já se manifestou no sentido de que a concessão ou não de benefícios sociais devem ser determinados pelo processo político democrático. Com isso, embora a Suprema Corte tenha tido oportunidades para extrair direitos sócio-econômicos de sua Bill of Rights como ocorrido no caso Deshaney versus Winnebago County Department of Social Services, ${ }^{27}$ ela, tem optado por assim não fazer.

Além disso, alguns juristas americanos chegaram a sustentar que, "realisticamente, os juizes por razões pragmáticas farão pouco para reforçar direitos positivos, mesmo quando estes forem formalmente reconhecidos pela Constituição. Se os juízes se envolvessem ativamente na tarefa de assegurar tais direitos, provavelmente fariam a situação piorar". ${ }^{28}$

28 Frank Cross. "The Error of Positive Rights" 48 UCLA Law Review 857 a 924. 
Naturalmente, há sempre o risco de cortes conservadoras, ao invés de garantir esses direitos, adotarem uma interpretação tão restritiva do elenco constitucional de direitos fundamentais que ao final os indivíduos poderiam ficar totalmente desprotegidos. A "Lockner Era" é lembrada por David Beatty para demonstrar que tal hipótese pode se transformar realidade. ${ }^{29}$

Mas apesar em risco existir, é ele um risco válido especialmente quando em geral o resultado é mais positivo do que negativo. Nos julgados analisados para este estudo, as cortes brasileiras, indianas e mesmo as sul-africanas vêm fazendo um esforço para assegurar o direito à saúde. Adotando ou não as melhores técnicas, essas decisões judiciais tendem a fazer uma efetiva diferença na vida dos indivíduos.

Logo, é hora de analisar alguns dos casos disponíveis nessas jurisdições.

\section{Brasil}

Certos juristas brasileiros acreditam que embora o direito à saúde seja justificável, as cortes podem somente forçar o Governo a elaborar políticas públicas. Fábio Konder Comparato diz que "é claramente impossivel compelir o Estado a providenciar imediatamente, a todos os que o demandem, um posto de trabalho, uma moradia, uma vaga em creche, um tratamento médico-cirúrgico de alta complexidade, e outras prestações dessa natureza." ${ }^{30}$ Entende o mesmo que a Constituição Federal não cria uma relação jurídica direta entre o Estado e os indivíduos, razão pela qual não há nenhum direito subjetivo imediato. Estes surgirão apenas como efeito indireto depois do estabelecimento das políticas públicas.

Parece, entretanto, que as cortes brasileiras não concordam com esta posição. Como será demonstrado, decisões judiciais vêm adotando uma atitude muito ativa e, contrariamente à lição de Comparato, estão considerando a saúde um direito subjetivo.

Mas não foi sempre assim. Imediatamente após a promulgação da Constituição Federal em 1988, juízes defendiam que a norma garantidora do direito à saúde era meramente uma norma programática e não podia criar direitos subjetivos para os indivíduos. ${ }^{31}$ Neste sentido, o Ministro do Superior Tribunal de Justiça, Demócrito Reinaldo, afirmou que "o grande número de preceitos constitucionais. alguns deles já citados, pouca valia têm para obrigar os Poderes Públicos a se esmerarem na proteção da saúde, educação e outros interesses essenciais à vida em sociedade.

29 David Beatty. Human Rights and Judicial Review: A Comparative Perspective. Boston: M. Nijhoff. 1994, p. 357.

30 Fábio Konder Comparato. O Ministério Público na Defesa dos Direitos Econômicos, Sociais e Culturais disponível em www.escoladegovemo.com.br/estcurso/dirhum.htm

31 Processo $\mathrm{n}^{\circ}$ 95.0068782-8 foi um dos primeiros casos analisados nesta matéria e segue esse entendimento. O STJ, então, decidiu que a norma constitucional garantidora do direito à saúde somente poderia ser vista como norma programática já que simplesmente protegia um interesse geral. Como a referida norma não trazia o conteúdo e extensão do direito, seria necessário aguardar até que o Legislativo editasse uma lei reguladora de tal direito. Julgamento publicado no Diário de Justiça de 17/06/1996. 
Estão inscritos na Constituição como um programa, como o fim que o Estado deve sempre perseguir..." 32

O entendimento dominante, entretanto, foi alterado em fase posterior. O Supremo Tribunal Federal, por exemplo, adotou uma nova visão sobre a questão. Em um caso decidido pela Corte constitucional, decidiu-se que o autor, HIV-positivo, deveria receber de graça do Estado os medicamentos necessários para mantê-lo vivo. ${ }^{33}$ A fundamentação dada pelo STF baseou-se principalmente na relação entre o pedido formulado pelo autor e o direito à vida, assim como no dever do Governo de implementar políticas públicas para garantir a todos o acesso a serviços de saúde.

Além disso, também se mencionou o artigo 196 da Constituição e foi dito que, mesmo considerando o referido mandamento uma norma programática, ele não poderia ser transformado em mera promessa constitucional. Ademais, quando se decidiu sobre a admissibilidade de um recurso interposto no processo citado, o Ministro Relator, Celso de Mello, entendeu que o direito à saúde deveria prevalecer sobre o que chamou um interesse financeiro e secundário do Estado.

Conseqüentemente, pode-se ver que as cortes brasileiras dão prioridade ao direito à saúde por causa de sua ligação com o direito à vida e à dignidade humana. Elas já determinaram que o Estado fornecesse a indivíduos o que fosse necessário para permanecerem vivos ou ao menos para permanecerem vivos mais tempo: um medicamento específico, um aparelho para problemas cardíacos, ${ }^{34}$ um tratamento médico para pessoas seriamente doentes mesmo quando não houvesse nenhuma perspectiva de cura. ${ }^{35}$

As cortes brasileiras, portanto, não consideram as questões de alocação de recursos públicos e dos limites estabelecidos pela doutrina da separação dos poderes, quando o direito à saúde está em jogo. Atribuem a este direito um peso quase absoluto, ao mesmo tempo em que tomam os outros fatores envolvidos como meros interesses secundários do Estado.

Índia

Tendo examinado a estratégia das cortes brasileiras, é hora de examinar a posição adotada pelas cortes da Índia.

Se os juízes brasileiros se dizem comprometidos com a garantia ao direito à saúde, o Judiciário indiano demonstra ainda mais determinação para atingir o mesmo

32 Demócrito Reinaldo. "A AIDS e o Poder Judiciário." AJURIS 72/7.

33 Recurso Extraordinário n 27.1286. Julgamento publicado no Diário de Justiça de 24/1 1/00.

34 TRF da $2^{a}$ Região - REO n 2000.02.01.002521-9. Julgamento publicado no Diário de Justiça da União em 19/06/2001.

35 Na AMS $n^{\circ} 2002.02 .01 .004116-7$ o autor, que sofria de câncer, requereu que fosse tratado num hospital público especializado. O TRF da $2^{\star}$ Região decidiu que, independentemente da possibilidade de cura, ele tinha direito à assistência médica. Julgamento publicado no Diário de Justiça da União em 25.07.2002. 
objetivo. Isto se percebe em razão da estrutura constitucional da Índia e da interpretação dada pelo Judiciário às normas envolvendo o direito à vida e à saúde.

A Constituição indiana de 1950 fez uma distinção entre direitos fundamentais e direito à saúde. Assim, enquanto a seção da Constituição intitulada "Direitos Fundamentais" garante os direitos civis e políticos, uma outra seção, chamada "Princípios Diretivos", regula os direitos sócio-econômicos, e, conseqüentemente, o direito à saúde. ${ }^{36}$

Os Princípios Diretivos foram introduzidos pela Assembléia Constitucional como meras instruções e objetivos sociais e econômicos a serem perseguidos pelo Governo ao adotar políticas públicas. E para não deixar nenhuma dúvida sobre esta realidade, a Constituição declara que "as provisões contidas nesta seção não podem ser impostas por nenhuma corte" (art. 37). Daí que esses princípios não foram elaborados como regras obrigatórias e vinculantes, como ocorre na Constituição brasileira.

Analisando a sistemática adotada pelo Estado indiano, Etienne Mureinik conclui que papel mais importante foi claramente dado aos direito civis, enquanto ao direito à saúde foi atribuído um papel secundário. Em suas próprias palavras, "fazer dos direitos econômicos meras presunçōes interpretativas, é o mesmo que declará-los de menor valor do que os direitos de primeira geração" 37

Não obstante, como oportunamente será aprofundado, esta situação foi dramaticamente mudada durante os anos 80 , através dos precedentes da Corte Suprema indiana. Jeremy Cooper sustenta que a corte em tela passou a ter consciência de que a interpretação da Constituição não deveria ser equiparada à interpretação da legislação ordinária. Disso resultou uma revolução nos seus julgados ${ }^{38}$ Desde então, o direito à saúde passou a ser considerado um direito fundamental naquela jurisdição, e, em consequiência, implementado e garantido por decisões judiciais.

Sendo assim, o primeiro fato que deve ser ressaltado é o forte ativismo judicial dos juízes indianos. O restante aconteceu automaticamente em decorrência do entendimento quanto ao papel constitucional dos mesmos.

Os juízes da Suprema Corte em particular comprometeram-se a promover uma efetiva melhora social, como pode ser concluído das palavras de P. N. Bhagwati, ex-juiz da Suprema Corte indiana: ${ }^{39}$

"Nós na Índia estamos nos afastando do formalismo e nos aproximando da utilização do ativismo judicial para alcançar justiça social ou distributiva, e nesta expressão eu incluo direitos humanos básicos. Nós acreditamos

36 "Art. 47 - Dever do Estado de aumentar o nivel de nutrição e os padrões de vida do povo e melhorar a saúde pública."

37 Etienne Mureinik. Op. cit., p. 468.

38 Jeremy Cooper. "Poverty and Constitutional Justice: The Indian Experience", 44 Mercer Law Review, 611 a 618.

39 P. N. Bhagwati. "The Role of the Judiciary in the Democratic Process". (1992) 3 Journal of Human Rights Law and Practice, 8 a 14. 
firmemente que o Judiciário moderno não pode se esconder atrás de noções de justiça legal quando questões de justiça social lhe são dirigidas." 40

Este ativismo judicial deu origem a novas técnicas processuais e substantivas, que têm marcado a concretização de direitos sócio-econômicos naquele país apesar de diversas críticas. É dito, por exemplo, que esta atitude alargou a função do Judiciário, uma questão que já foi oportunamente analisada no presente estudo.

Por considerar estes obstáculos teóricos meramente luxo de acadêmicos, o Judiciário se utiliza de ações judiciais para compelir o Estado a tomar medidas para garantir o direito à saúde. Essas ações, portanto, possuem como objetivo principal a pressão judicial sobre o Governo. Sendo assim, o resultado para as partes do processo é secundário. ${ }^{41}$

Quais são, então, essas novas técnicas que fizeram o Judiciário indiano tão famoso? Como dito antes, elas compreendem regras processuais e substantivas.

No primeiro caso, a Suprema Corte instituiu o que é chamado Litigância no Interesse Público ("Public Interest Litigation"). De acordo com a Corte, "a tarefa de reestruturar a ordem social e econômica de modo que os direitos sociais e econômicos se transformem numa realidade significativa para o pobre e para a parcela humilde da comunidade é uma que pertence legitimamente ao Legislativo e ao Executivo, mas a mera iniciação de programas de resgate social e econômico pelo Executivo e pelo Legislativo não seria suficiente. E é somente através de estratégias multidimensionais, onde se inclui a Litigância de Interesse Público que estes programas de salvação social e econômica podem se tomar eficazes." 42

Através de um procedimento especial, as regras de legitimidade foram ampliadas e mesmo formalidades processuais foram ignoradas. Sob o artigo 32 (l) da Constituição indiana, qualquer pessoa que pro bono publico quiser propor uma ação contra uma violação de direitos humanos perante a corte será autorizada a assim agir, se o grupo de vítimas da violação não tiver nenhum acesso à corte, principalmente por causa de condições de pobreza. Devido a tal flexibilidade, jornalistas, ONGs e outras organizações puderam chamar a atenção da Corte Constitucional para casos envolvendo circunstâncias terríveis em hospitais públicos, ${ }^{43}$ desrespeito de direitos sociais de crianças e mulheres ${ }^{44}$ etc...

40 Todavia, esse entendimento não foi adotado desde a promulgação da Constituição em 1950. Segundo Jeremy Cooper, de 1950 a 1970 a Corte Constitucional era considerada grande protetora dos ricos, impedindo inclusive a implementação de algumas reformas sociais. Foi somente em 1980 que esse cenário foi alterado, graças a uma mudança na composição da Corte, que passou então a adotar uma nova postura em relação à interpretação constitucional (Jeremy Cooper. Op. cit., p. 613).

41 Ibid., p. 618.

42 People's Union for Democratic Rights v. Union of Índia (1982 AIR SC 1472).

43 Rakesh Chandra Narayan v. State of Bihar (1989 AIR SC 348).

44 People's Union for Democratic Rights v. Union of Índia (1982 AIR SC 1472). 
A fim de facilitar a iniciativa das pessoas, a jurisdição epistolar foi criada, significando que nenhuma formalidade será requerida para contactar a corte. Cartas e mesmo cartões-postais já foram aceitos pela Suprema Corte como uma maneira de iniciar um procedimento. E, como Jeremy Cooper explica, para evitar que o ônus da prova recaia sobre os autores, depois desse contato inicial, a corte nomeia uma comissão para produzir e recolher as provas dos fatos. ${ }^{45}$

Além disso, através da análise dos casos de Litigância no Interesse Público, pode-se ver que as ordens judiciais proferidas são bem características. Elas geralmente contêm instruções a serem seguidas pelo Governo, em alguns casos inclusive sob o monitoramento da corte judicial, como aconteceu no caso Rakesh Chandra. Lá, a Suprema Corte constituiu um comitê de gerência para ajudá-la. Em outros casos, como indicado por Jamie Cassels, essas orientações são realmente "detalhadas, específicas e intrusivas", ${ }^{46}$ fazendo delas decisões de natureza administrativa. ${ }^{47}$

O segundo mecanismo desenvolvido pela Corte Suprema relaciona-se à interpretação constitucional. A corte concluiu que interpretar a Constituição não é o mesmo que interpretar diplomas legais, já que a primeira atividade envolve a aplicação dos valores mais importantes de um sistema jurídico: os valores constitucionais. ${ }^{48} \mathrm{E}$ entre esses valores, a mesma corte inclui direitos sócio-econômicos.

Devido a esse novo entendimento, foi dado ao direito à vida - encontrado no artigo 21 da Constituição indiana - uma enorme amplitude. Desde os anos 80, tal previsão constitucional inclui também o direito aos meios de subsistência, já que de outra forma, a corte sustenta, seria possível privar um indivíduo de sua vida não por ações diretas, mas removendo os meios de sobrevivência. ${ }^{49} \mathrm{E}$ ambas as situações não podem ser permitidas sem o procedimento estabelecido por lei.

No caso Chameli Singh, a corte foi mais longe ainda. Como compreendeu que o direito à vida não significa simplesmente "uma existência animal", ela decidiu que este direito fundamental "implica num direito à alimentação básica, água, ambiente decente, educação, assistência médica e abrigo". ${ }^{50} \mathrm{E}$ foi esse o ponto inicial para a efetiva proteção do direito à saúde, mesmo considerando sua inclusão dentre os Princípios Diretivos da Constituição indiana e não como direito fundamental.

45 Jeremy Cooper, Op. cit., p. 625.

46 Jamie Cassels. "Judicial Activism and Public Interest Litigation in India: Attempting the Impossible", 37 The American Journal of Comparative Law, 495 a 506.

47 No caso Vikram Deo Singh Tomar, a corte decidiu que bens como lençóis e cobertores deveriam ser fornecidos aos internos, além da frequiência com que os médicos deveriam visitar a instituição. (1988 AIR SC 1782).

48 P. N. Bhagwati, Fundamental Rights in their Economic, Social, and Cultural Context, in 1988 Commonwealth Secretarial 57.

49 Olga Tellis v. Bombay Municipal Corporation (1986 AIR SC 180).

50

Chameli Singh v State U.P. (1996 2 SCC 549). 
Assim, através de uma interpretação extremamente criativa, a Corte Suprema transformou o direito à saúde - um direito sócio-econômico - em um direito fundamental na Constituição indiana.

Em relação especificamente aos trabalhadores, eles afirmaram explicitamente que "o direito à saúde, assistência médica para proteger a saúde e vigor de um trabalhador quando em serviço ou após a aposentadoria é um direito fundamental sob o artigo $21, \mathrm{c} / \mathrm{c}$ os artigos $39(e), 41.4348 \ldots . .51$

Conseqüentemente, a Corte Suprema emiti ordens para que o Estado proteja e promova o direito à saúde da população necessitada. Como exemplo, determinou-se que medicamentos prescritos deveriam estar disponíveis aos pacientes de uma clínica psiquiátrica pública, não obstante os custos daí decorrentes. ${ }^{52}$

Percebe-se assim, que a Corte Suprema indiana adota uma posição, na realidade, contraditória. Apesar de sustentar que o Governo não pode ser forçado a fornecer meios de subsistência adequados, ${ }^{53}$ profere decisões que forçam o Governo nesse sentido, uma vez que as mesmas se encontram cheias de obrigações positivas. Assim, enquanto em teoria o conteúdo do art. 37, primeira parte, da Constituição é reconhecido, na prática, parece que a mesma corte negligencia tal limitação e através da interpretação fez o direito à saúde justiciável.

A maneira como a Suprema Corte indiana praticamente reescreveu a Constituição e as regras de legitimidade processual para garantir o direito à saúde demonstra a filiação ao pensamento bem interessante de um dos membros da "House of Lords" - órgão judiciário máximo da Inglaterra - Lorde Reid. Segundo ele, "houve uma época em que era quase indecente se sugerir que os juizes faziam a lei - eles somente a declaravam. ... Mas nós não acreditamos mais em conto de fadas." ${ }^{54} \mathrm{E}$ esta ideologia, que parece quase sem limites, mostra como os juízes na Índia são muito mais destemidos do que os juízes brasileiros.

África do Sul

De forma semelhante à Constituição brasileira, a Constituição da África do Sul, promulgada em 1996, inseriu o direito à saúde no seu elenco de direitos fundamentais. ${ }^{55}$ Após o fim do regime de Apartheid, foi decidido que esta nova Constituição

51 Consumer Education and Research Centre and others v. Union of india and others (AIR 1995 SC 922).

52 Rakesh Chandra Narayan v. State of Bihar (1989 AIR SC 348).

53 Olga Teilis v. Bombay Municipal Corporation (1986 AIR SC 180).

54 Lorde Reid. "The Judge as Law Maker" 12 Journal of the Society of Public Teachers of Law 22 a 22.

55 "Seção 27 - saúde, alimentação, água e seguridade social

(1) Todos têm direito a ter acesso a:

(a) Serviços de saúde, incluindo tratamentos de fertilidade;

(b) Alimentação e água suficientes; $e$

(c) Seguridade social, incluindo, se eles forem incapacitados de sustentar a si e a seus dependentes, assistência social apropriada. 
deveria trazer uma melhoria real para a vida dos sul-africanos. Assim a introdução do direito à saúde e outros direitos sócio-econômicos entre os direitos fundamentais foi uma efetiva tentativa nesse sentido apesar de, no fim, terem sido qualificados pela seção 36 do mesmo documento, conhecida como cláusula de limitação genérica.

A fim de enfatizar o compromisso para construir uma sociedade justa, rejeitou-se na referida lista de direitos fundamentais a distinção, muito comum, entre direitos civis e políticos de um lado e direitos sócio-econômicos de outro. Contrariamente ao Brasil, a África do Sul adotou a doutrina da indivisibilidade e interdependência dos direitos humanos, e colocou o direito à saúde junto com direitos como igualdade e liberdade de religião - típicos direitos civis. Logo, não se criou nenhuma distinção entre estes direitos fundamentais.

Entretanto, apesar do pioneirismo em certos aspectos, há menos atitude em outros. Mesmo estando comprometido com um objetivo similar - garantir o direito à saúde -, é possível observar que, na estratégia adotada pela África do Sul, as cortes têm uma grande deferência pelo Legislativo e Executivo.

Para começar, qualquer dúvida que pudesse existir naquela jurisdição a respeito da justiciabilidade do direito à saúde desapareceu após o Julgamento de Certificação ("Certificate Judgement") da Suprema Corte. A este respeito foi explicado que:

"Nós somos da opinião que estes direitos são, ao menos em alguma extensão, justificáveis. Como nós afirmamos no parágrafo precedente, muitos dos direitos civis e políticos encontrados no novo texto trarão implicações orçamentárias similares sem comprometer sua justiciabilidade. O fato que os direitos sócio-econômicos causarão quase inevitavelmente tais ônus não nos parece ser uma barreira à sua justiciabilidade." ${ }^{66}$ (minha ênfase)

Entretanto, a questão sobre a extensão da interferência dos juízes permaneceu em aberto. A primeira oportunidade para a Corte Constitucional emitir uma posição sobre isso foi no caso Soobramoney v. Minister of Health, ${ }^{57}$ onde o autor era um homem que estava em estágio final de insuficiência renal crônica e teve negado o respectivo tratamento em um hospital público. Em consequiência, o mesmo propôs uma ação visando garantir seu direito à vida, previsto na seção 11 da Constituição da África do Sul, assim como o direito ao tratamento de emergência garantido pela seção 27(3) do mesmo documento.

Ao decidir o caso, a Corte Constitucional rejeitou ambos os argumentos e extinguiu o caso. Infelizmente, o autor faleceu algum tempo após o julgamento.

(2) O Estado deve adotar medidas, legislativas e de outras naturezas razoáveis, dentro dos recursos disponíveis, para atingir uma realização progressiva de cada um desses direitos.

(3) Ninguém poderá ter recusado tratamento médico de emergência"

56 Caso CCT23/96 - 1996 (4) SA 744 (CC). Esse julgamento histórico buscou a certificação judicial da nova Constituição da África do Sul, ou seja, certificar que as novas provisões constitucionais observavam certos princípios contidos na Constituição então em vigor.

571998 (1) SA 765 (CC). 
A respeito do direito à vida, a corte não lhe deu a mesma amplitude dada pelos juízes indianos. De forma contrária, eles adotaram uma visão bem mais restrita, onde apenas as obrigações negativas foram extraídas do direito constitucional à saúde. Nenhum dever de fornecer meios de subsistência foi imposto ao Governo, apesar da corte defender em tese que "uma interpretação generosa seja dada aos direitos para assegurar que os individuos obtenham a proteção completa do elenco constitucional de direitos humanos." 58

Em seguida, se considerou que o direito à vida e à saúde deveriam ser aplicados separadamente. A justificativa dada para tanto foi que o Bill of Rights sul-africano tem uma seção própria para o direito à saúde. Por essa razão, não seria possível fazer inferências a partir de outros direitos.

A corte, ademais, não elaborou o conteúdo ou mesmo um conceito nuclear que o direito à saúde deveria ter sob o Bill of Rights. O único aspecto efetivamente decidido foi que os tratamentos de saúde caros não estão incluídos neste direito.

Pior ainda foi a conclusão a que chegou a Corte Constitucional sobre o posicionamento a ser adotado no exame de casos futuros. Analisando os argumentos levantados pelo réu (ausência de recursos financeiros e razoabilidade da política adotada pelo hospital para escolher seus pacientes), a corte entendeu que "essas escolhas envolvem decisões difíceis de serem tomadas no nível politico ao fixar o orçamento da saúde, e no nivel funcional ao se decidir sobre as prioridades a serem escolhidas. A Corte será lenta em interferir com decisões racionais tomadas de boa-fé pelos órgãos políticos e pelas autoridades médicas cuja responsabilidade é tratar de tais questões" (minha ênfase).

Essa posição, que para alguns quase equivale à abdicação da prestação jurisdicional, ${ }^{59}$ vai de encontro ao entendimento adotado pela mesma corte no Julgamento de Certificação.

Entretanto, Scott e Alston sugerem que esta autolimitação deve ser vista como algo relativo, porque deverá aparecer somente quando a corte estiver convencida da racionalidade da política adotada pelo Estado. ${ }^{60}$ Assim, essa decisão não seria um sinal de não envolvimento por parte do Judiciário. E, de qualquer maneira, esse foi o primeiro julgamento sobre direitos sócio-econômicos da Corte Constitucional, uma instituição que ainda estava aprendendo a lidar com tal questão.

Os mesmos juristas nos lembram que esta decisão foi proferida no ano seguinte ao da promulgação da Constituição sul-africana de 1996, mostrando que a corte estava ciente do até então limitado período de tempo para o início das ações estatais de implementação do direito à saúde. Por esta razão, esperou-se que em decisões posteriores o Judiciário não fosse tão tolerante.

58 Soobramoney v. Minister of Health - 1998 (1) SA 765 (Constitutional Court).

59 (2000) 16 South African Journal of Human Rights, 206 a 241.

60 Craig Scott e Philip Alston. "Adjudicating Constitutional Priorities in a Transnational Context: A Comment on Soobramoney's Legacy and Grootboom's Promise". (2000) 16 South African Journal of Human Rights, 206 a 241. 
Em 2000, o caso Grootboom foi proposto perante a Corte Constitucional. Embora o direito à saúde não estivesse envolvido diretamente, mas sim o direito à moradia, garantido pela seção 26 da Constituição, este julgamento seria fundamental para aquele, posto que significaria uma oportunidade para um aprimoramento da estratégia adotada pela Corte em tela em relação à proteção de direitos sócioeconômicos.

E neste caso, finalmente, a existência de um conceito nuclear foi reconhecida, quando a Corte Constitucional determinou que políticas públicas para serem razoáveis precisam "oferecer algum alivio para aqueles que não têm nenhum acesso à terra, nenhum telhado sobre suas cabeças, e que estão vivendo em circunstâncias intoleráveis ou situações de crise." ${ }^{61}$ Uma vez que a política pública contestada não garantia nenhum alívio deste tipo, ela foi julgada irrazoável.

Ao Governo, em consequiência, foi requisitado o planejamento de outro programa de moradia, só que desta vez considerando sua obrigação de levar em conta aqueles em circunstâncias desesperadas. Parecia, assim, que mesmo respeitando o Executivo, aqueles juízes tinham passado a adotar uma estratégia mais ativa e estariam preparados agora para proteger adequadamente os direitos sócio-econômicos. Além disso, a corte parecia estar pela primeira vez seguindo a posição esposada no Julgamento de Certificação.

Mas posteriormente verificou-se que a realidade era diferente, como ficou comprovado pelo julgamento proferido no caso Minister of Health \& Others $v$. Treatment Action Campaign \& Others ${ }^{62}$ em 2002. Esse processo levou a grandes discussões jurídicas entre os sul-africanos, já que se tratava de uma tentativa de reduzir a transmissão de AIDS para bebês recém-nascidos, um dos principais problemas daquele país atualmente.

$\mathrm{Na}$ ocasião do julgamento, a corte analisou inicialmente a possibilidade de elaboração de um conceito central do direito à saúde, e adotando uma visão diferente da encontrada em Grootboom concluiu que " as cortes não estão institucionalmente equipadas para proceder a amplos questionamentos fáticos e políticos, necessários para determinar quais os padrões mínimos do direito à saúde".

Com isso, a Corte Constitucional da África do Sul considerou que os juízes estariam limitados ao exame da razoabilidade dos padrões estipulados pelo Legislativo, nunca podendo determinar quais seriam esses padrões.

Ademais, a referida corte optou por não seguir a posição do Comitê de Direitos Econômicos, Sociais e Culturais, ${ }^{63}$ já que entendeu que os atributos mínimos dos direitos sócio-econômicos seriam também dependentes de recursos financeiros e não

612001 (1) SA 46.

62 Caso CCT 8/02 de 5 de julho de 2002.

63 O Comitê dos Direitos Econômicos, Sociais e Culturais, em seu Comentário Geral $\mathrm{n}^{\circ}$ 14, afirmou que "os Estados-membros não podem, em nenhuma circunstância sequer, justificar o não-cumprimento das obrigações centrais estabelecidas no parágrafo 43, que são não-derrogáveis." UN doc. E/C. $12 / 2000 / 4$. 
precisariam ser fornecidos imediatamente. A Corte Constitucional esclareceu o seguinte:

"É impossivel dar a todos imediatamente o mesmo o acesso a um serviço "minimo". Tudo que é possivel, e tudo que pode se esperar do Estado, é que esse aja razoavelmente para fornecer acesso aos direitos sócio-econômicos identificados nas seções 26 e 27 de uma forma progressiva"

Tendo chegado a essas conclusões a respeito do núcleo do direito à saúde, a corte passou a analisar o pedido principal formulado no caso. Concluíram, então, que a política pública contestada pelos autores não era razoável e conseqüentemente inconstitucional.

Conseqüentemente, determinou-se que o Governo removesse, no setor de saúde pública, as restrições à disponibilidade de Nevirapine, um medicamento para impedir a transmissão de AIDS durante o parto de mãe para filho. Além disso, a corte entendeu que o Governo deveria adotar um programa para garantir o direito de mulheres e crianças aos serviços de saúde relacionados ao combate do HIV.

Todavia, apesar do fato de o fabricante concordar em fornecer esse medicamento de graça para a África do Sul por cinco anos, a corte entendeu que a decisão proferida não significava que o tratamento deveria estar imediatamente disponível a todas as mulheres grávidas. Preferiu, portanto, deixar o Governo seguir o seu próprio ritmo.

Esse específico entendimento mostra quão reverente a Suprema Corte sul-africana continua sendo. Eles estão se esforçando para encontrar uma maneira de garantir na prática o direito à saúde, sem desrespeitar os outros poderes. Entretanto, como Geraldine Van Bueren coloca, respeito não pode ser interpretado como submissão. ${ }^{64}$

Por isso, entendo que, contrariamente à opinião de Ivan Hare, para quem os julgamentos da Suprema Corte da África do Sul fornecem um significativo alívio para a população pobre, ${ }^{65}$ uma corte determinada a apoiar os direitos sócio-econômicos deve adotar uma posição mais forte nesta seara. Isso não significa que se deve seguir o Brasil ou os juízes indianos, que certamente representam o outro extremo. Mas significa que devem, sim, perseguir esse objetivo de forma mais eficaz.

\section{$V-$ Conclusão}

$\mathrm{O}$ direito à saúde é muito precioso aos indivíduos. Além de contribuir para o gozo dos direitos civis e políticos - como acontece com todo direito sócio-econômico - , o direito à saúde é fortemente ligado ao direito à vida e à dignidade da pessoa humana. Por outro lado, entretanto, ele é normalmente conceituado de uma maneira imprecisa, retirando-lhe grande parte da eficácia e tornando polêmica sua conceituação.

64 Geraldine Van Bueren, "Including the Excluded: The Case for an Economic, Social and Cultural Human Rights Act", 2002 Public Law, 456 a 464.

65 Ivan Hares. Op. cit., p. 630. 
A falta do consenso a respeito do direito à saúde é encontrada também entre juízes. Como pode ser visto dos julgamentos proferidos pelos Judiciários brasileiro, indiano e sul-africano, entendimentos diversos foram desenvolvidos e adotados.

No Brasil e na Índia, como muito peso é atribuído à ligação entre o direito à saúde e o direito à vida, as cortes tendem a incluir quase tudo no conceito nuclear do primeiro, tal como tratamento médico e medicamentos custosos.

De forma contrária, a Corte Constitucional da África do Sul não dá o mesmo peso ao vínculo com o direito à vida. Entende-se naquela jurisdição que ambos os direitos devem ser aplicados independentemente. Em razão dessa interpretação, o direito à saúde lá perdeu parte de sua força e proteção.

Entendimentos diversos existem não só no tocante à substância do direito à saúde, mas também em relação à extensão com que essas cortes podem intervir em favor desse direito. Juízes brasileiros e indianos interferem significativamente em políticas públicas na área de saúde e freqüentemente determinam prioridades, independentemente das considerações do Governo. Ao mesmo tempo, os juízes sul-africanos são exageradamente deferentes ao Executivo e ao Legislativo.

Esta discordância é resultante, a meu ver, da dificuldade de se alcançar um equilibrio entre dois extremos: a realização de um direito garantido constitucionalmente e o respeito pelas funções institucionais do Legislativo e do Executivo. Este é o grande desafio da justiciabilidade do direito à saúde.

Esta dificuldade, todavia, não pode desanimar os juízes de tentar. A mais importante conclusão a se extrair das experiências aqui analisadas é que as cortes não são meras guardiãs formais dos direitos fundamentais. Ao lembrar aos Governos dos seus deveres constitucionais, as cortes transformaram-se em relevantes e concretos instrumentos de proteção do direito à saúde.

O Comitê de Direitos Econômicos, Sociais e Culturais adota a mesma visão a respeito da capacidade das cortes em seu Comentário Geral $n^{\circ} 9$. Lá se afirmou que "a adoção de uma classificação rígida dos direitos econômicos, sociais e culturais que os põe, por definição, fora do alcance das cortes seria arbitrário e incompatível com o princípio que os dois grupos de direitos humanos são indivisiveis e interdependentes. Também reduziria drasticamente a capacidade das cortes de proteger os direitos dos grupos mais vulneráveis e necessitados na sociedade." 66

\section{Bibliografia}

ALEXY, Robert. A Theory of Constitutional Rights. Oxford: OUP. 2002.

BEATTY, David. Human Rights and Judicial Review: A Comparative Perspective. Boston: M. Nijhoff. 1994.

BERLIN, Isaiah. "Two Concepts of Liberty", in Four Essay on Liberty. Londres: OUP. 1969. 
BHAGWATI, P.N.. "The Role of the Judiciary in the Democratic Process" (1992) 3 Journal of Human Rights Law and Practice, 8

"Fundamental Rights in their Economic, Social, and Cultural Context, in 1988 Commonwealth Secretariat 57.

CANOTILHO, J.J. Gomes. Direito Constitucional, Coimbra, Livraria Almedina, 1989.

CAPPELLETTI, Mauro. "The Future of Legal Education. A Comparative Perspective". (1992) 8 South African Journal of Human Rights 1.

CASSELS, Jamie. "Judicial Activism and Public Interest Litigation in Índia: Attempting the Impossible" 37 The American Journal of Comparative Law 495.

COMPARATO, Fábio Konder. “O Ministério Público na Defesa dos Direitos Econômicos, Sociais e Culturais", disponível em.

COOLEY, Thomas. A Treatise on the Law of Torts, Chicago, Callaghan and Co. 1988.

COOPER, Jeremy, "Poverty and Constitutional Justice: The Indian Experience", 44 Mercer Law Review, 611.

CRAVEN, Matthew, "The Justiciability of Economic, Social and Cultural Rights" in Economic, Social and Cultural Rights: Their Implementation in the United Kingdom, R. Burchill, D. Harris \& A. Owers, (eds.) 1999.

CROSS, Frank. "The Error of Positive Rights", 48 UCLA Law Review, 857.

DAVIS, DM. "The Case Against the Inclusion of Socio-Economic Demands in a Bill of Rights Except as Directive Principies" (1992) 8 South African Journal of Human Rights 475.

DE VOS, Pierre. "Pious Wishes or Directly Enforceable Human Rights?: Social and Economic Rights in South Africa's 1996 Constitution", (1997) 13 South African Journal of Human Rights 67.

ELY, John Hart. Democracy and Distrust: A Theory of Judicial Review. Londres: Harvard University Press. 1980.

FELDMAN, David, Civil Liberties and Human Rights in England and Wales, Oxford: OUP. 2002.

FELDMAN, Jonathan. "Separation of Powers and Judicial Review of Positive Rights Claims: The Role of State Courts in an Era of Positive Government", 24 Rutgers Law Journal, 1057.

HARES, Ivan. "Minister of Health v. Treatment Action Campaign: The South African AIDS Pandemic and the Constitutional Right to Healthcare". 2002 European Human Rights Law Rewiew 624.

HART, H.L.A. "O Conceito de Direito". Lisboa: Fundação Calouste Gulbenkian.

MELLO, Celso Antônio Bandeira de. "Eficácia das Normas Constitucionais sobre Justiça Social" em 1981 Revista de Direito Público, n 57-58.

MUREINIK, Etienne. "Beyond a Charter of Luxuries: Economic Rights in the Constitution" (1992) 8 South African Journal of Human Rights, 464.

REID, Lorde. "The Judge as Law Maker" 12 Journal of the Society of Public Teachers of Law 22.

REINALDO, Demócrito. “AIDS e o Judiciário”. AJURIS 72/7. 
SACH, Albie. "Justiciability of Social, Economic and Cultural Rights". Palestra dada na London School of Economics and Political Science em 27/02/2003.

SARLET, Ingo Wolfgang. A Eficácia dos Direitos Fundamentais. Porto Alegre: Livraria do Advogado, 2001.

SCOTT, Craig e Patrick Macklem. "Constitutional Ropes of Sand or Justiciable Guarantees? Social Rights in a New South África Constitution" 141 University of Pennsylvania Law Review 1.

SCOTT, Craig e Philip Alston. "Adjudicating Constitutional Priorities in a Transnational Context: A Comment on Soobramoney's Legacy and Grootboom's Promise". (2000) 16 South African Journal of Human Rights 206.

SHAH, Sheetal. "Illuminating the Possible in the Developing Worid: Guaranteeing the Human Right to Health in Índia" 32 Vanderbilt Journal of Transnational Law 435.

SRIPATI, Vijayashri. "Human Rights in India: Fifty Years After Independence".26 Denver Journal of international Law and Policy 93.

STEINER, Henry e Philip Alston. International Human Rights in Context: Law, Politics, Morals, Oxford, OUP, 2000.

TOEBES, Brigit. "The Right to Food" in Economic, Social and Cultural Rights: A Textbook. Eide et. al (eds.) Londres: M. Nijhoff. 2001.

TOMASEVSKI, Katarma. "The Right to Health" in Economic, Social and Cultural Rights: A Textbook. Eide et. al. (eds.) Londres: M. Nijhoff. 1995.

VAN BUEREN, Geraldine, "Including the Excluded: The Case for an Economic, Social and Cultural Human Rights Act", 2002 Public Law 456. "Alleviating Poverty Through the Constitutional Court", (1999) 15 South African Journal of Human Rights 52. 


\section{A Nova Família: \\ Problemas e Perspectivas}

\section{Orgainizador: Vicente Barretto}

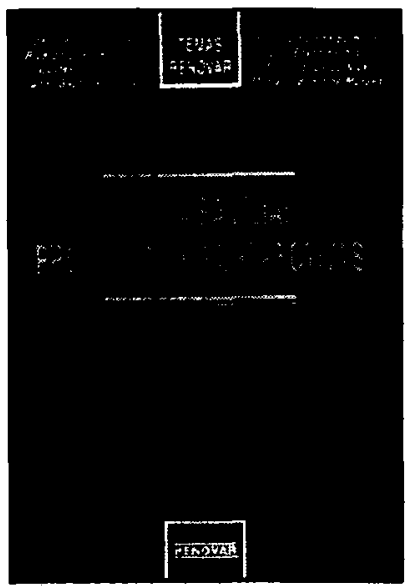

A reuniāo de textos sobre a "nova família", especialmente escritos por seus autores para a Coleção Temas Renovar, pretende trazer para a literatura jurídica brasileira novos métodos para a análise do fenômeno jurídico. Escolheu-se propositadamente um fato social - as novas formas de relaçōes familiares -, que tem suscitado acalorados debates tanto entre juristas, como na opinião pública de uma forma geral, e que representa uma radical transformação no modelo de familia, estabelecido no direito civil clássico.

Ref. 0146

Form. 14x21

Brochura

1997

198 págs.

\section{A Origem do Direito de Solidariedade}

\section{José Fernando de Castro Farias}

Este livro aborda temas centrais: a revolta contra o formalismo jurídico, direito e justiça, direito e experiência, os mecanismos jurídicos de gestāo do social, o discurso solidarista, o paradigma da solidariedade e o solidarismo jurídico. Os enunciados do direito de solidariedade fazem parte de uma mesma formação discursiva, baseando-se em mecanismos comuns, cuja investigação passa por um estudo da História das Idéias Jurídicas, e, mais precisamente, por uma abordagem arqueológica do direito que remonta à Europa do fim do século XIX e do início do século XX.

Ref. 0166

Brochura

Form. 14x21 1998

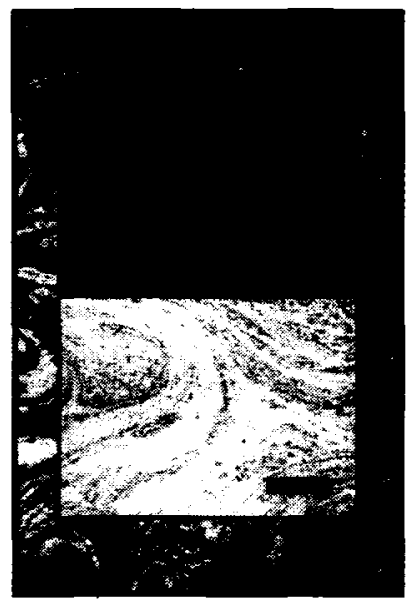

